\title{
Trends in clinical features and survival of oral cavity cancer: fifty years of experience with 3,362 consecutive cases from a single institution
}

This article was published in the following Dove Press journal: Cancer Management and Research

\author{
Shu-Wei Chen ${ }^{1-3, *}$ \\ Quan Zhang ${ }^{1-3, *}$ \\ Zhu-Ming Guol-3 \\ Wen-Kuan Chen ${ }^{1-3}$ \\ Wei-Wei Liul-3 \\ Yan-Feng Chen ${ }^{1-3}$ \\ Qiu-Li Li ${ }^{1-3}$ \\ Xue-Kui Liu ${ }^{1-3}$ \\ $\mathrm{HaO} \mathrm{Li}^{1-3}$ \\ Dian Ou-Yang ${ }^{1-3}$ \\ Wei-Chao Chen ${ }^{1-3}$ \\ Xiao-Yan Fu ${ }^{1-3}$ \\ Xi-Di Wang ${ }^{1-3}$ \\ An-Kui Yang ${ }^{1-3}$ \\ Jin-Xin $\mathrm{Bei}^{2-4}$ \\ Ming Song ${ }^{1-3}$ \\ 'Department of Head and Neck \\ Surgery, Sun Yat-sen University \\ Cancer Center, ${ }^{2}$ State Key Laboratory \\ of Oncology in South China, \\ ${ }^{3}$ Collaborative Innovation Center of \\ Cancer Medicine, ${ }^{4}$ Department of \\ Experimental Research, Sun Yat-sen \\ University Cancer Center, Guangzhou, \\ Guangdong, China
}

*These authors contributed equally to this work

Correspondence: Ming Song; Jin-Xin Be Sun Yat-sen University Cancer Center, 65I Dongfeng Dong Road, Guangzhou, 510060, Guangdong, China

Tel +86 208734 3300; +862039336779 Fax +86 208734 377I; +862087343I70 Email songming@sysucc.org.cn; beijx@sysucc.org.cn
Background: Global data demonstrate minimal improvement in the survival rate for oral cavity cancer (OCC) patients. We wished to know whether or not clinical features and survival rate have changed over time for OCC patients receiving initial treatment and follow-up at a large cancer center in China.

Methods: Clinical features and survival data were collected on patients diagnosed during the successive decades of 1960-1969 ( $\mathrm{n}=253), 1970-1979$ ( $\mathrm{n}=497), 1980-1989(\mathrm{n}=659), 1990-1999$ ( $\mathrm{n}=793)$, and 2000-2009 ( $\mathrm{n}=1,160)$ at the Sun Yat-sen University Cancer Center.

Results: Over time, the overall 5-year survival rate for OCC patients was 52.0\%. According to tumor localization, this rate was $71.4 \%$ for lip cancer, $56.3 \%$ for oral tongue cancer, and $42.7 \%$ for other parts of the oral cavity. From the 1960 s to the 2000 s, the 5 -year survival rate steadily improved from $47.8 \%$ to $55.6 \%(P<0.001)$. Survival steadily decreased with age and was higher for women than for men in the 3 most recent decades. The survival rate for male patients was constant over time, while the rate for female patients improved dramatically. Obvious trends in clinical features over time included the following: increasing age of patients, increasing proportions of localized disease at diagnosis, decreasing proportions of diagnoses of lip cancer, decreasing proportions of diagnoses of squamous cell carcinoma, and decreasing proportions of non-surgical treatment approaches.

Conclusion: The survival rate has steadily improved for OCC patients at this cancer center. Keywords: oral cavity cancer, clinical features, survival, treatment modality

\section{Background}

Despite various diagnostic and therapeutic advances in recent years, cancer is still a significant public health concern worldwide. ${ }^{1}$ Overall, 14.1 million new cancer cases and 8.2 million cancer-specific deaths were reported in $2012 .{ }^{2}$ Among these, estimates of 300,400 new cases and 145,400 deaths of oral cavity cancers (OCCs) were reported, which represented $2.1 \%$ and $1.8 \%$ of all new cancers and cancer-specific deaths, respectively, making OCC the eleventh most common cancer and the twelfth largest cancer killer in men. Two-thirds of the disease burden is within the developing world, where OCC ranks eighth in incidence and ninth in mortality in men.

OCC is ranked as the sixth most frequently occurring malignancy in Asia; however, the national incidence and mortality rates of OCC in China are lacking. ${ }^{3}$ The agestandardized incidence rate of OCC was 4.72 per 100,000 males and 2.38 per 100,000 females in Hong Kong and 1.97 per 100,000 males and 1.71 per 100,000 females in Shanghai (period of diagnoses 1998-2002, according to the Cancer Incidence in Five 
Continents data system). ${ }^{4}$ In Taiwan, OCC affected 27.04 males and 3.17 females per 100,000 in the population, ${ }^{5}$ which is now the predominant cause of cancer-related mortality in Taiwanese men 25-44 years old. A survival analysis of 2,324 OCC patients, diagnosed from 1990-2001 and followed up to 2003 from 4 population-based cancer registries in China (Hong Kong, Qidong, Shanghai, and Tianjin), yielded a 5-year age-standardized relative survival rate of $67 \%{ }^{6}$ Obviously, the reported survival rate is much higher than observed nationally, which could not completely represent the treatment outcome nationally.

In most parts of the world, OCCs occur predominantly in the oral tongue, and a large majority of OCCs are squamous cell carcinomas (SCCs). ${ }^{7}$ In spite of recent advances in the treatment of OCC, no major improvement in survival rates has been reported from population-based survival studies in the past decades. ${ }^{8}$ Early diagnoses and treatments remain pivotal to improved survival rates. Although we have no easy means to determine whether or not the survival of OCC has improved in China nationally, we do have a robust cancer registry that we have used to record clinic-pathologic characteristics, stage at diagnosis, and survival rate for OCC patients treated at the Sun Yat-sen University Cancer Center (SYSUCC). The SYSUCC, one of the largest cancer centers in China, is located at Guangzhou and has been the primary referral and treatment center for OCC in southern China.

We examined whether or not survival rates changed during the past 50 years and how any changes in stage, histology, and treatment related to changes in survival.

\section{Methods}

\section{Data sources}

For this retrospective study, we used the SYSUCC medical record database to identify OCC patients diagnosed from 1960 to 2009 . The year 1960 was chosen as a starting point because the SYSUCC treated its first OCC patient in that year. The year 2009 was chosen as the closing year in order to have 5 successive decades and to provide a minimum follow-up of at least 5 years for patients diagnosed in the most recent year. During this 50-year period, a total of 4,033 OCC patients were treated at the SYSUCC. This study excluded 671 patients because of recurrent or residual disease after primary treatment elsewhere $(n=536)$ or incomplete or loss of clinical data $(n=135)$. Thus, a total of 3,362 previously untreated patients with histologically confirmed OCC were enrolled in this study.

Data regarding the patients' gender, age at diagnosis, histology, oral cavity subsite, and stage were obtained from the database. The patients ranged in age from 3 to 90 years (mean age $\pm \mathrm{SD}, 53 \pm 13$ years); of this group, 2,238 (66.6\%) were men and 1,124 (33.4\%) were women. The overall follow-up was defined as the time interval between the date of initial therapy and the date of the last consultation or death. Followup of vital status was performed until June 2015. Median post-therapeutic follow-up time was 74 months (range 1-602 months), and $94.3 \%$ of patients had follow-up into the fifth year after initial therapy. The focus was on observed survival for all patients and general stage. General stage was used for these comparisons to ensure the consistency of definition over time because of the lack of detailed tumor, node, and metastases staging documented in medical records in the previous period of the study. General staging definitions were used for subset analyses. Local disease was defined by invasive cancer without local extension or any metastases. Regional disease was defined by local extension and/or cervical lymph node metastases. Distant disease was defined by distant metastases.

\section{Classification of anatomic sites}

According to the tenth revision of the International Statistical Classification of Diseases and Related Health Problems (ICD-10), OCCs included cancers of the lip (ICD-10 code $\mathrm{C} 00$ ), tongue ( $\mathrm{C} 02$ ), and other parts of the oral cavity (gingiva $\mathrm{C} 03$, floor of mouth $\mathrm{C} 04$, hard palate C05.0, and buccal mucosa C06.0). ${ }^{9}$ Cancers of the following sites were excluded from this study: base of the tongue (ICD-10 code C01) and soft palate (C05.1). When an intraoral lesion overlapped 2 sites, the primary tumor localization was defined as the site where the majority of the lesion was located. All patients were histologically confirmed as malignancies of the oral cavity, among which an overwhelming majority ( $~ 90 \%)$ were SCCs.

\section{Statistical analyses}

Descriptive statistics were used to examine demographic variables for the patients during each of the 5 successive decades. The study used chi-squared tests to compare proportions. The age groups were defined as: 0-44, 45-54, 55-64, 65-74, and $\geq 75$ years, which were in accordance with the International Cancer Survival Standards. ${ }^{10}$ All-cause 5-year overall survival rates were calculated using the method of Kaplan and Meier. The overall survival rate was calculated for each of the 5 successive decades, respectively. The time period of 2000-2009, which corresponds to the most recent decade for which follow-up data were available, was specifically noted. Log-rank tests were used to compare specific survival rate curves, which were based on deaths at monthly intervals. The overall survival rate by age, gender, histological type, stage, and therapy was presented for overall cancers of 
the oral cavity, as well as cancer of the lip, oral tongue, and other parts of the oral cavity. All data analyses in the present study were carried out with the software package SPSS 16.0. Statistical significance was defined by $P<0.05$.

\section{Ethics approval}

The study was reviewed and approved by the ethics committee of the SYSUCC. All cases involved in the study consented to participate and the informed consent obtained was written. There was no patient of $<18$ years of age at the time of the study.

\section{Results}

\section{Patient characteristics}

Table 1 summarizes the characteristics of patients enrolled for each decade. There was an increase in the mean age for each patient cohort. The male-to-female ratio of patients stayed approximately $2: 1$ over time. In terms of histological type, there was an increase in minor salivary gland carcinoma (MSGC), concurrent with decreases in SCC and other types. As for tumor localization, the proportion of oral tongue cancer was steady, accounting for slightly more than one-half of all cases; there was a gradual decline in the proportion of lip cancer and a corresponding increase in the proportion of cancer of other parts of the oral cavity. The proportion of patients who had localized disease at diagnosis was increasing. As for initial therapies, surgery was the main treatment modality over time. More than two-thirds of OCC patients underwent surgery or surgery-based multimodality therapy as their initial treatment. There has been an increase in the use of surgery alone.

Table S1 summarizes the characteristics of patients diagnosed with other pathologic types other than SCC and MSGC.

Table I Demographic data for oral cavity cancer patients in successive decades, 1960-2009

\begin{tabular}{|c|c|c|c|c|c|c|c|}
\hline & All & $1960-1969$ & $1970-1979$ & $1980-1989$ & $1990-1999$ & 2000-2009 & $P$ \\
\hline Patients, $\mathbf{n}$ & 3,362 & 253 & 497 & 659 & 793 & 1,160 & \\
\hline Age at diagnosis, years & & & & & & & $<0.001$ \\
\hline Mean age \pm SD & $53.0 \pm 13.0$ & $49.6 \pm 13.0$ & $50.2 \pm 12.8$ & $51.3 \pm 12.7$ & $54.4 \pm 13.0$ & $54.9 \pm 12.7$ & \\
\hline Age range & $3-90$ & $4-79$ & $6-82$ & 13-84 & $3-88$ & $6-90$ & \\
\hline Gender, \% (n) & & & & & & & 0.215 \\
\hline Male & $66.6(2,238)$ & $64.8(164)$ & $68.0(338)$ & $64.3(424)$ & $69.5(55 I)$ & $65.6(76 I)$ & \\
\hline Female & $33.4(1,124)$ & $35.2(89)$ & $32.0(159)$ & $35.7(235)$ & $30.5(242)$ & 34.4 (399) & \\
\hline Type, \% (n) & & & & & & & 0.080 \\
\hline $\mathrm{SCC}$ & $89.7(3,014)$ & $93.3(236)$ & $89.6(445)$ & $87.3(575)$ & $89.7(7 I I)$ & $90.3(1,047)$ & \\
\hline MSGC & $5.4(182)$ & $2.4(6)$ & $4.8(24)$ & $7.4(49)$ & $4.8(38)$ & $5.6(65)$ & \\
\hline Others & $4.9(166)$ & $4.3(\mathrm{II})$ & $5.6(28)$ & $5.3(35)$ & $5.5(44)$ & $4.1(48)$ & \\
\hline Tumor localization, \% (n) & & & & & & & $<0.001$ \\
\hline Lip & $4.6(153)$ & $13.0(33)$ & $8.7(43)$ & $2.7(18)$ & $3.9(31)$ & $2.4(28)$ & \\
\hline Oral tongue & $56.6(1,904)$ & $57.3(145)$ & $57.1(284)$ & $57.4(378)$ & $57.6(457)$ & $55.2(640)$ & \\
\hline Other parts & $38.8(1,305)$ & $29.7(75)$ & $34.2(170)$ & $39.9(263)$ & $38.5(305)$ & $42.4(492)$ & \\
\hline Floor of mouth & $7.7(258)$ & $1.6(4)$ & $5.2(26)$ & $4.9(32)$ & $9.1(72)$ & $10.7(124)$ & \\
\hline Gingiva & I4.7 (494) & II.I (28) & $13.1(65)$ & I4.I (93) & |4.9 (I | 8) & I 6.4 (I90) & \\
\hline Hard palate & $8.2(276)$ & $5.5(14)$ & $9.1(45)$ & I I.2(74) & $7.2(57)$ & $7.4(86)$ & \\
\hline Buccal mucosa & $8.2(277)$ & I I.5 (29) & $6.8(34)$ & $9.7(64)$ & $7.3(58)$ & $7.9(92)$ & \\
\hline Stage, \% (n) & & & & & & & $<0.001$ \\
\hline Local & $51.7(1,737)$ & $31.2(79)$ & $69.4(345)$ & $51.9(342)$ & $43.9(348)$ & $53.7(623)$ & \\
\hline Regional & $25.3(851)$ & $15.0(38)$ & $23.8(118)$ & 24.1 (159) & $21.2(168)$ & 31.7 (368) & \\
\hline Distant & $1.2(42)$ & $0.4(1)$ & $0.4(2)$ & I.I (7) & $1.2(10)$ & $1.9(22)$ & \\
\hline Unknown & $21.8(732)$ & $53.4(135)$ & $6.4(32)$ & $22.9(151)$ & 33.7 (267) & 12.7 (I47) & \\
\hline Therapy, \% (n) & & & & & & & $<0.00$ I \\
\hline Surgery & $71.3(2,397)$ & 70.3 (I78) & $68.6(341)$ & $68.6(452)$ & 74.5 (591) & $72.0(835)$ & \\
\hline Surgery alone & $46.6(1,567)$ & 45.4 (II5) & 47.7 (237) & $35.4(233)$ & $45.6(362)$ & $53.4(620)$ & \\
\hline Surgery with RT & $9.6(321)$ & $23.7(60)$ & $16.3(81)$ & $12.1(80)$ & $6.7(53)$ & $4.1(47)$ & \\
\hline Surgery with chemo & I 1.6 (391) & $0.8(2)$ & $3.2(16)$ & $14.7(97)$ & $17.4(138)$ & I I.9 (138) & \\
\hline Surgery with RT and chemo & $3.5(118)$ & $0.4(I)$ & $\mathrm{I} .4(7)$ & $6.4(42)$ & $4.8(38)$ & $2.6(30)$ & \\
\hline Non-surgery & $22.3(750)$ & $29.3(74)$ & $27.4(136)$ & $25.5(168)$ & 19.7 (156) & $18.6(216)$ & \\
\hline RT alone & $8.3(280)$ & $26.5(67)$ & $23.6(117)$ & $9.9(65)$ & $2.4(19)$ & $1.0(12)$ & \\
\hline Chemo alone & $8.9(298)$ & $2.0(5)$ & $0.4(2)$ & 5.9 (39) & $10.7(85)$ & 14.4 (167) & \\
\hline RT with chemo & $5.1(172)$ & $0.8(2)$ & $3.4(17)$ & $9.7(64)$ & $6.6(52)$ & $3.2(37)$ & \\
\hline None & $6.4(215)$ & $0.4(I)$ & $4.0(20)$ & 5.9 (39) & $5.8(46)$ & 9.4 (109) & \\
\hline
\end{tabular}

Abbreviations: SCC, squamous cell carcinoma; MSGC, minor salivary gland carcinoma; RT, radiotherapy; chemo, chemotherapy. 


\section{Survival}

Table 2 shows the overall survival rate for all OCC patients in this 50-year period. Follow-up information was available for all patients, and $94.3 \%$ of the patients had follow-up into the fifth year after initial therapy. The overall 5-year survival rate amounted to $52.0 \%$ (Figure $\mathrm{S} 1$ ). The survival rate was associated with the patient's age, steadily decreasing from $59.6 \%$ for patients $\leq 44$ years to $30.7 \%$ for patients $\geq 75$ years (Figure 1A). If separated according to gender, the same pattern of a steadily decreasing survival rate with age was observed for both men and women. In general, the overall 5 -year survival rate was higher for women than for men in all age groups (women 55.8\% and men 50.1\%) (Figure 1B). Both histological type and tumor stage contributed to the level of survival rate (Figure 1C, D). As for initial therapy, the overall 5-year survival rate of patients who underwent surgery was much higher than those who underwent non-surgical treatment (60.6\% and 23.7\%, respectively) (Figure S2).

Table 3 and Figure 2 summarize the overall survival rate for OCC patients in successive decades (1960-1969, 19701979, 1980-1989, 1990-1999, and 2000-2009). The overall 5 -year survival rate amounted to $47.8 \%, 47.6 \%, 51.1 \%$, $52.2 \%$, and $55.6 \%$ for the 5 successive decades, respectively. Survival did increase steadily over time. In addition, survival steadily decreased with age and was higher for women than for men in the 3 most recent decades. The survival rate for male patients was steady, staying around $50 \%$ over time, while the rate for female patients improved dramatically, from $41.3 \%$ in the period $1960-1969$ to $65.0 \%$ in the period 2000-2009. As for tumor localization, the survival rate for cancer of the oral tongue improved from $45.5 \%$ in the period $1960-1969$ to $62.2 \%$ in the period 2000-2009.

Table S2 and Figure S3 show the overall survival rate for OCC patients by subsite. The overall 5-year survival rate of patients with lip cancer was $71.4 \%$. The overall 5 -year survival rate regarding cancer of the oral tongue was $56.3 \%$. Survival decreased with age, from $61.6 \%$ in patients $\leq 44$ years old to $31.5 \%$ in patients $\geq 75$ years old. The survival rate was higher for women (58.8\%) than for men $(54.9 \%)$. Tumor stage and histological type were strongly associated with survival rate; it varied between $67.7 \%$ for local stage tumors and $11.1 \%$ for cancers involving distant sites, as well as between $69.2 \%$ for MSGC and $56.1 \%$ for SCC. The survival rate of patients who underwent surgery $(66.2 \%)$ was much higher than for those who underwent non-surgical treatment $(26.3 \%)$. For cancer of oral cavity parts other than the lip and oral tongue, the overall 5-year survival rate was $42.7 \%$.

Table S3 and Figure S4 show that the overall 5-year survival rate was $38.7 \%, 42.2 \%, 48.1 \%$, and $44.8 \%$, for

Table 2 Five-year OS of patients diagnosed with oral cavity cancer by gender, 1960-2009

\begin{tabular}{|c|c|c|c|c|c|c|c|}
\hline \multirow[t]{2}{*}{ Factor } & \multirow[t]{2}{*}{ Level } & \multicolumn{2}{|c|}{ Overall } & \multicolumn{2}{|l|}{ Male } & \multicolumn{2}{|c|}{ Female } \\
\hline & & $\mathbf{N}$ & 5 -year OS (\%) & $\mathbf{N}$ & 5 -year OS (\%) & $\mathbf{N}$ & 5-year OS (\%) \\
\hline All & & 3,147 & 52.0 & 2,094 & 50.1 & $\mathrm{I}, 053$ & 55.8 \\
\hline \multirow[t]{5}{*}{ Age, years } & $\leq 44$ & 830 & 59.6 & 535 & 58.5 & 295 & 61.6 \\
\hline & $45-54$ & 795 & 54.7 & 535 & 51.3 & 260 & 61.7 \\
\hline & $55-64$ & 939 & 49.2 & 630 & 47.1 & 309 & 53.5 \\
\hline & $65-74$ & 480 & 44.4 & 334 & 43.9 & 146 & 45.4 \\
\hline & $\geq 75$ & 103 & 30.7 & 60 & 28.5 & 43 & 33.5 \\
\hline \multirow[t]{3}{*}{ Type } & SCC & 2,845 & 51.3 & 1,920 & 49.7 & 925 & 54.6 \\
\hline & MSGC & 167 & 70.0 & 85 & 65.0 & 82 & 74.9 \\
\hline & Others & 135 & 45.7 & 89 & 45.2 & 46 & 46.7 \\
\hline \multirow[t]{7}{*}{ Localization } & Lip & 148 & 71.4 & 108 & 72.0 & 40 & 69.6 \\
\hline & Tongue & I,823 & 56.3 & 1,150 & 54.9 & 673 & 58.8 \\
\hline & Other parts & $I, 176$ & 42.7 & 836 & 40.4 & 340 & 48.4 \\
\hline & Gingiva & 435 & 38.7 & 298 & 39.3 & 137 & 37.4 \\
\hline & Floor of mouth & 229 & 42.1 & 204 & 40.4 & 25 & 56.0 \\
\hline & Hard palate & 250 & 48.1 & 158 & 40.8 & 92 & 60.2 \\
\hline & Buccal mucosa & 262 & 44.8 & 176 & 41.9 & 86 & 50.7 \\
\hline \multirow[t]{4}{*}{ Stage } & Local & 1,689 & 63.4 & 1,099 & 61.3 & 590 & 67.1 \\
\hline & Regional & 785 & 32.2 & 535 & 32.1 & 250 & 32.4 \\
\hline & Distant & 27 & 13.5 & 20 & 14.0 & 7 & 14.3 \\
\hline & Unknown & 646 & 47.2 & 440 & 44.6 & 206 & 52.6 \\
\hline \multirow[t]{2}{*}{ Therapy } & Surgery & 2,397 & 60.6 & 1,554 & 59.6 & 843 & 62.5 \\
\hline & Non-surgery & 750 & 23.7 & 540 & 21.8 & 210 & 28.6 \\
\hline
\end{tabular}

Abbreviations: OS, overall survival; SCC, squamous cell carcinoma; MSGC, minor salivary gland carcinoma. 
A

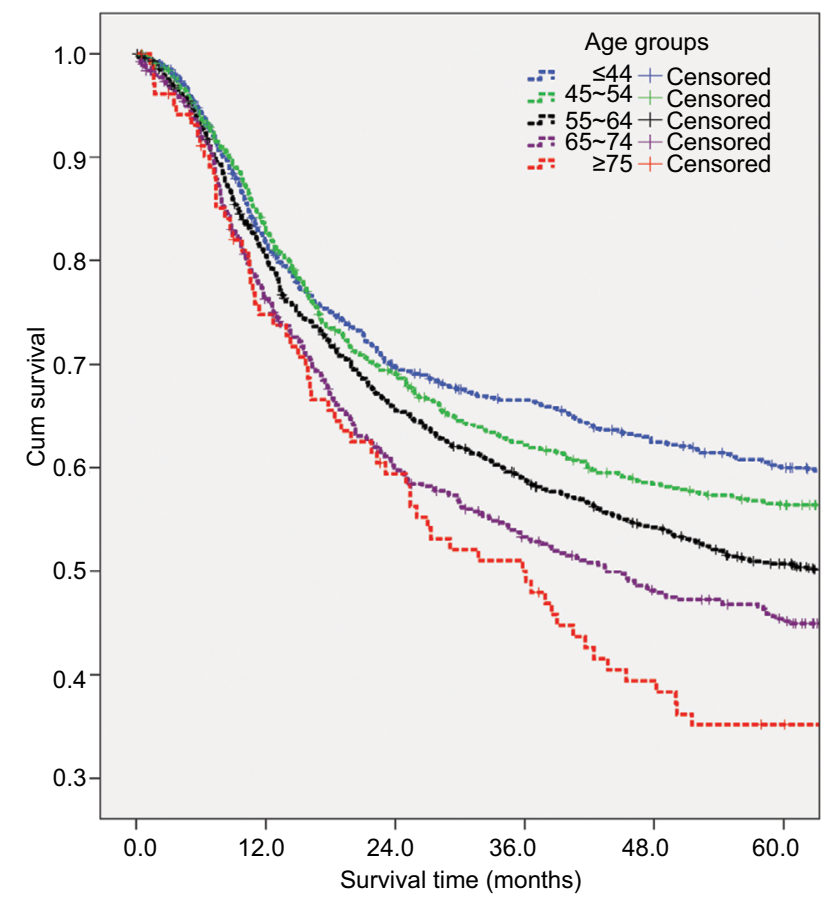

C

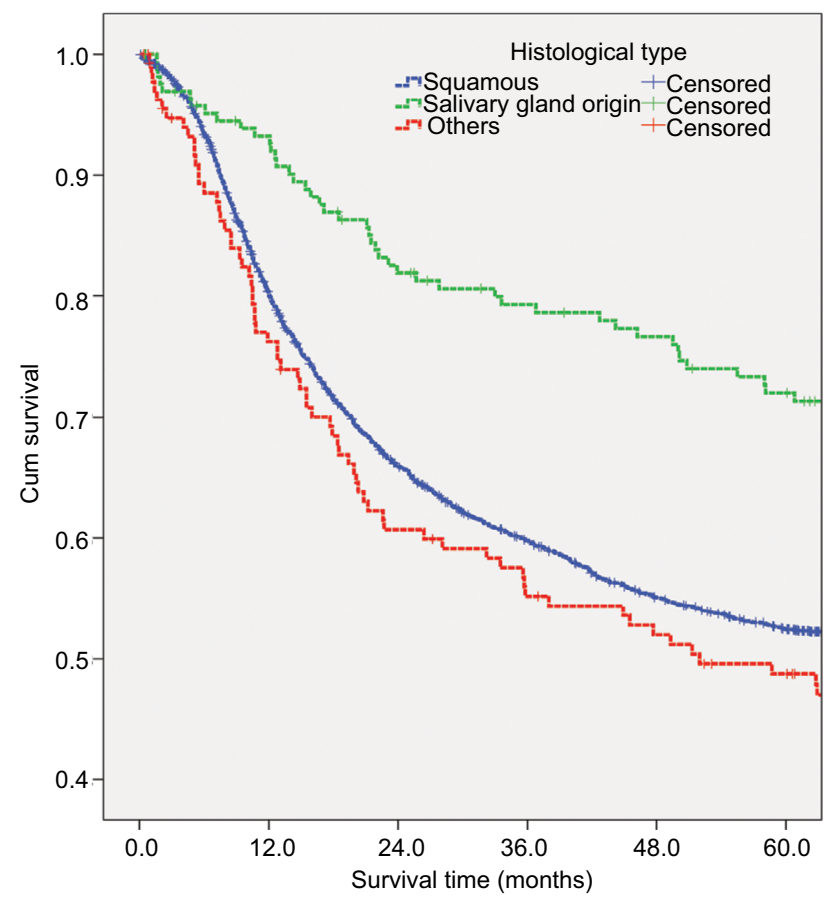

B

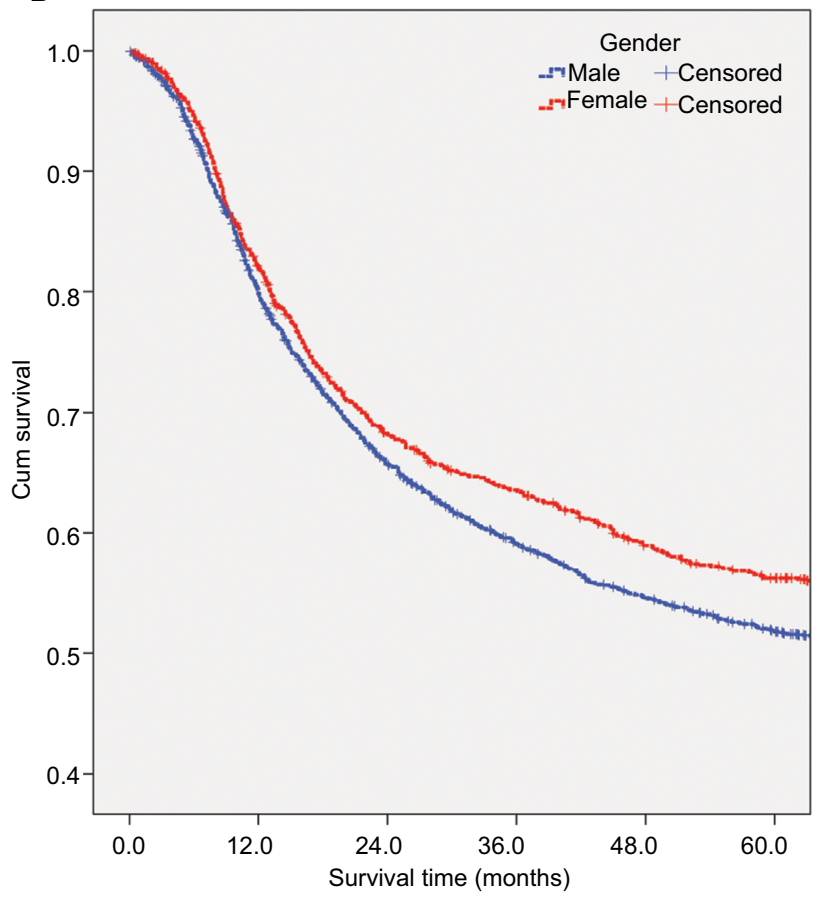

D

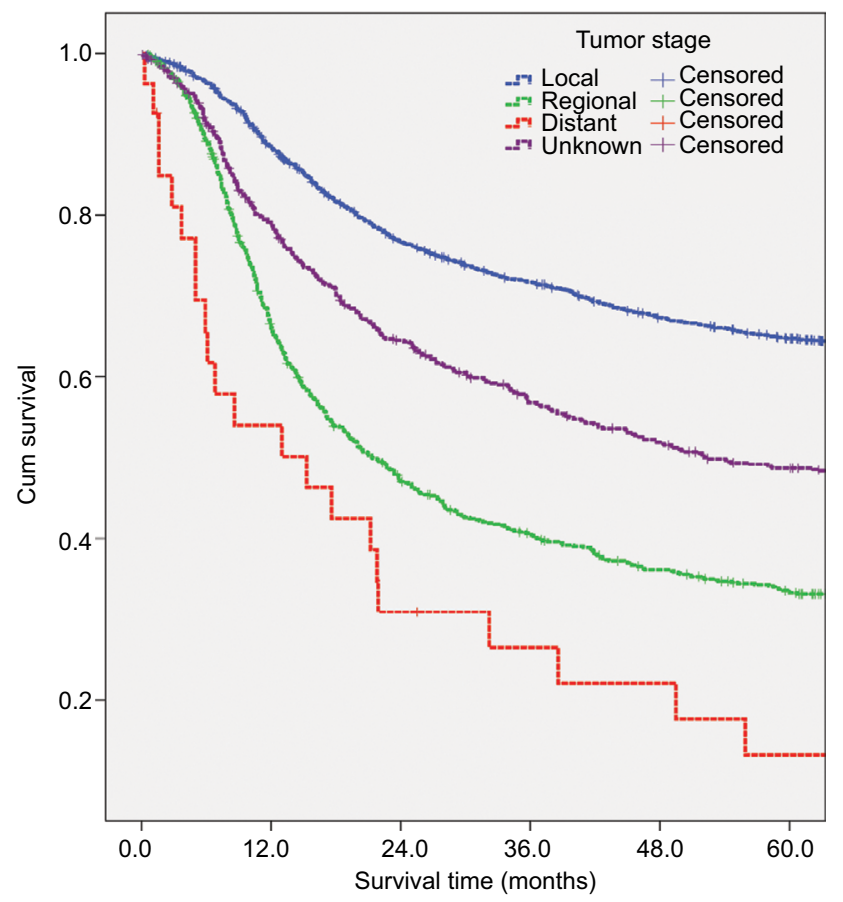

Figure I (A) Survival curves for all-cause mortality for patients diagnosed with oral cavity cancer in each of the age groups ( $\leq 44,45-54,55-64,65-74$, and $\geq 75$ years old) $(P<0.00$ I for all). (B) Survival curves for all-cause mortality for patients diagnosed with oral cavity cancer by gender $(P<0.00 \mathrm{I})$. (C) Survival curves for all-cause mortality for patients diagnosed with oral cavity cancer by histological type (squamous cell carcinoma, carcinoma of minor salivary gland, and others) $(P<0.00 \mathrm{I}$ for all). (D) Survival curves for all-cause mortality for patients diagnosed with oral cavity cancer by tumor stage (local, regional, distant, and unknown) ( $P<0.00 \mathrm{I}$ for all).

Abbreviation: cum, cumulative.

cancers of the gingiva, floor of mouth, hard palate, and buccal mucosa, respectively. The relationship of survival and histological type, tumor stage, and initial therapy is similar to the pattern described previously.
Table S4 focuses on the most recent decade, 2000-2009, according to gender and tumor localization and represents the treatment outcome in the recent years. The pattern in survival with respect to clinical features was comparable 
Table 3 Five-year overall survival of patients diagnosed with oral cavity cancer in successive decades, 1960-2009

\begin{tabular}{|c|c|c|c|c|c|c|}
\hline Factor & Level & $1960-1969$ (\%) & | $970-1979$ (\%) & | $980-1989(\%)$ & 1990-1999 (\%) & 2000-2009 (\%) \\
\hline All & & 47.8 & 47.6 & 51.1 & 52.2 & 55.6 \\
\hline \multirow[t]{5}{*}{ Age, years } & $\leq 44$ & 49.2 & 49.8 & 57.0 & 67.9 & 66.5 \\
\hline & $45-54$ & 59.1 & 51.3 & 52.5 & 52.2 & 58.6 \\
\hline & $55-64$ & 44.8 & 42.8 & 51.7 & 48.8 & 51.6 \\
\hline & $65-74$ & 26.9 & 47.5 & 36.5 & 42.8 & 50.8 \\
\hline & $\geq 75$ & 50.0 & 22.2 & 34.2 & 28.6 & 32.2 \\
\hline \multirow[t]{2}{*}{ Sex } & Male & 51.2 & 50.4 & 49.1 & 49.6 & 50.5 \\
\hline & Female & 41.3 & 41.5 & 54.7 & 57.9 & 65.0 \\
\hline \multirow[t]{7}{*}{ Localization } & Lip & 72.7 & 61.0 & 76.5 & 69.9 & 84.1 \\
\hline & Tongue & 45.5 & 48.4 & 55.2 & 57.9 & 62.2 \\
\hline & Other parts & 40.5 & 42.6 & 43.1 & $4 I .1$ & 43.9 \\
\hline & Floor of mouth & 50.0 & 45.8 & 51.1 & 45.1 & 35.8 \\
\hline & Gingiva & 30.6 & 39.3 & 39.4 & 30.3 & 45.6 \\
\hline & Hard palate & 28.6 & 35.7 & 53.6 & 57.8 & 47.8 \\
\hline & Buccal mucosa & 54.8 & 54.5 & 33.3 & 42.0 & 47.2 \\
\hline \multirow[t]{3}{*}{ Type } & $\mathrm{SCC}$ & 48.2 & 47.1 & 50.8 & 51.0 & 54.4 \\
\hline & MSGC & 66.7 & 59.1 & 68.1 & 74.2 & 74.0 \\
\hline & Others & 27.3 & 45.2 & 26.4 & 52.0 & 60.5 \\
\hline \multirow[t]{4}{*}{ Stage } & Local & 70.8 & 52.6 & 64.2 & 61.3 & 69.3 \\
\hline & Regional & 28.9 & 32.6 & 27.8 & 38.5 & 31.2 \\
\hline & Distant & 0 & 0 & 25.0 & 15.0 & 12.5 \\
\hline & Unknown & 39.5 & 50.2 & 44.3 & 48.7 & 55.9 \\
\hline \multirow[t]{2}{*}{ Therapy } & Surgery & 56.0 & 52.9 & 60.3 & 60.5 & 65.1 \\
\hline & Non-surgery & 27.0 & 34.1 & 25.1 & 19.6 & 17.6 \\
\hline
\end{tabular}

Abbreviations: SCC, squamous cell carcinoma; MSGC, minor salivary gland carcinoma.

with the pattern described previously for all patients in the 50-year period.

\section{Discussion}

This comprehensive hospital-based study provides detailed data on survival for 3,362 OCC patients treated at a large cancer center in southern China and shows that survival rate has steadily improved over the past 50 years. The explanation for this improvement is multifactorial. There have been many improvements in the diagnosis and treatment of OCC during these past 50 years in China. As the largest cancer center in southern China, founded over 50 years ago, the SYSUCC has witnessed tremendous improvements in cancer management. After the reform and opening-up policy in the 1980s, the Chinese people began to enjoy a relatively high socioeconomic status with access to high-quality healthcare. In addition, Chinese physicians were able to access the latest advances in the diagnosis and management of OCC and were well aware of the importance of multidisciplinary and interdisciplinary OCC care. Patients diagnosed with OCC benefited from the modern treatment concepts and medical facilities, especially female patients, whose overall 5 -year survival rate improved over time by $>20 \%$ points. An increasing proportion of patients who had localized disease at diagnosis and a decreasing proportion of patients with an unknown stage were seen over time. This was attributed to popularized imaging techniques and improved clinician documentation of stage. More and more patients are diagnosed at an early stage of OCC when surgery alone may be curative. Above all, earlier diagnosis, more accurate staging, and correspondingly more accurate treatment seem to contribute to the improved survival rate.

In this study, the survival rate of OCC patients generally decreased with age, whether analyzed for all patients or separated according to gender, which was in accordance with data reported elsewhere. ${ }^{11}$ If separated according to tumor localization, the same pattern of decrease in survival rate with age was observed for cancers of all subsites except for the lip.

The oral tongue is the most cancer-prone, intraoral site in most populations. ${ }^{7,12}$ Our findings demonstrated that oral tongue cancer accounted for more than half of all cases, and the overall 5-year survival rate of oral tongue cancer improved from $45.5 \%$ in the $1960-1969$ period to $62.2 \%$ in the 2000 2009 period. The survival rate of female patients even reached $69.9 \%$. In comparison, the overall 5-year survival rates of tongue cancer in developed countries were as follows: USA $63.4 \%,{ }^{13}$ Germany $44.9 \%$ (male) $/ 56.0 \%$ (female), ${ }^{11}$ Denmark $35 / 45 \%$, Finland 50/68\%, Norway $48 / 58 \%$, and Sweden 


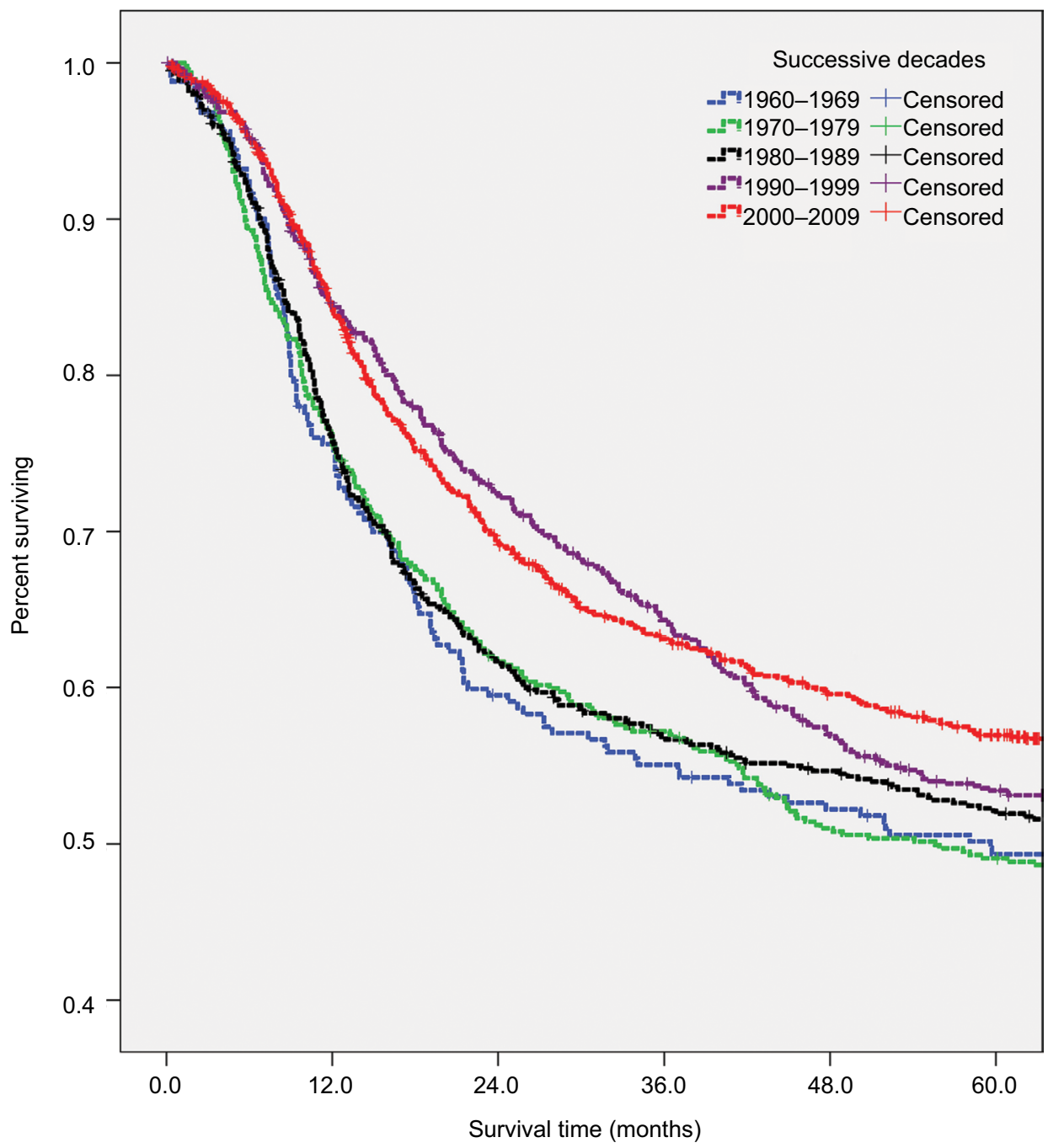

Figure 2 Survival curves for all-cause mortality for patients diagnosed with oral cavity cancer in each of the successive decades 1960-1969, 1970-1979, 1980-1989, 1990-1999, and 2000-2009 ( $P<0.001$ for all).

$46 / 56 \% .{ }^{14}$ In general, the aforementioned data indicate a tendency toward similar survival rates between the USA and this study and slightly higher survival rates for oral tongue cancer patients in this study than observed in European countries. We may conclude that we are reaching the international level in treating oral tongue cancer. However, the survival of patients with cancers of the lip and other parts of the oral cavity was lower than that reported from the USA and the European countries. ${ }^{11,13}$ For lip cancers, this might be attributed to the relatively low incidence of lip cancers in China and thus lack of treatment experience. For cancers of the other parts of the oral cavity, especially the gingiva and hard palate, this might be attributed to the relatively conservative surgical procedure in the past, as a result of overemphasizing the quality of life after treatment. This situation has been greatly improved in the last decade since the treatment concept has changed with the international guidelines.

Histological type is an important prognostic factor. SCC is the most common histological type of OCC, accounting for about $90 \%$ of all cases in most populations worldwide. MSGC is a rare and distinctive malignancy in the oral cavity, with conspicuous clinical features, including no gender difference in incidence, slow growth, non-aggressive, rare metastasis, and mostly favorable prognosis despite metastases and recurrences. ${ }^{15,16}$ According to this study, the male-tofemale ratio of MSGC is about 1:1, which is quite different from that of SCC (about 2:1). The hard palate was the most common subsite involved for MSGC (54.5\%), followed by gingiva (14.4\%) and buccal mucosa (10.8\%). As for SCC, the most common subsites were as follows: oral tongue (63.2\%), 
gingiva $(12.2 \%)$, and buccal mucosa $(8.1 \%)$. Furthermore, the survival distinction between different histological types was significant. The 5-year survival rate of patients with MSGC was $70.0 \%$, which was almost $20 \%$ higher than that of patients with SCC (51.3\%) and about $25 \%$ higher than that of patients with other histological types (45.7\%).

In the development history of treating OCC, surgical treatment is considered the mainstay of multimodal treatment because prospective and retrospective data demonstrate significantly better survival rates among surgically treated patients. ${ }^{17-19}$ Through the 50-year period of this study, surgery or surgery-based multimodality therapy was the main initial treatment modality. The survival rate of patients who underwent surgery was much higher than those who underwent non-surgical treatment. Recent advances in induction chemotherapy with agents, such as cisplatin and fluorouracil, may have contributed to lower distant failure rates and better organ preservation in locally advanced head and neck cancer patients. ${ }^{20}$ In addition, targeted drugs, such as cetuximab, have been shown to have favorable loco-regional control and additional survival benefits in locally advanced head and neck cancers. These drugs also have survival benefits in distant metastatic and/or recurrent head and neck cancers, which might well provide promising treatment choices for locally advanced OCC patients in the future. ${ }^{21,22}$ However, extensive data from large randomized trials on the treatment efficacy of induction chemotherapy or targeted drugs for locally advanced OCC patients are lacking. ${ }^{23,24}$ Currently, wide resection and reconstruction with a pedicle or free flap is widely used, and it is largely acceptable that non-surgical treatment modality should be limited for unresectable/inoperable or recurrent patients.

\section{Conclusion}

Our results show that survival of OCC patients has steadily improved over time in China. The overall survival improvement is largely attributable to the survival improvement of female OCC patients. However, the limited improvement of overall 5-year survival for male OCC patients reminds us of the pivotal importance of enhanced efforts of primary prevention to reduce the disease burden of OCCs, since a considerably large proportion of OCCs are smoking related and thus avoidable. To summarize, the present study is the first to provide comprehensive information about clinical features and 5-year overall survival of OCC patients treated at one of the largest cancer centers in China. Over the past 50 years (1960-2009), patients with cancers of the lip, oral tongue, and other parts of the oral cavity were shown to have a 5-year overall survival of $71.4 \%, 56.3 \%$, and $42.7 \%$, respectively. In the most recent decade (2000-2009), the survival amounted to $84.1 \%, 62.2 \%$, and $43.9 \%$, respectively. More effort should be put into the management of OCC in China, especially for male patients.

\section{Acknowledgments}

We acknowledge Xin-lin Chen who directed the statistical analysis. The study was funded by the National Natural Science Foundation of China (number 81672671).

\section{Author contributions}

MS and JB designed the study. SC wrote the manuscript. $\mathrm{MS}, \mathrm{AY}$, and QZ reviewed and edited the manuscript. SC, WcC, XF, and XW obtained the patients' clinicopathological characteristics from the SYSUCC medical record database. $\mathrm{SC}, \mathrm{ZG}$, and $\mathrm{YC}$ were in charge of the follow-up data acquisition. XL, HL, and DO were in charge of the quality control of data. WkC, WL, and QL analyzed the data. All authors read and approved the final manuscript.

\section{Disclosure}

The authors report no conflicts of interest in this work.

\section{References}

1. Torre LA, Bray F, Siegel RL, Ferlay J, Lortet-Tieulent J, Jemal A. Global cancer statistics, 2012. CA Cancer J Clin. 2015;65(2):87-108.

2. Ferlay J, Soerjomataram I, Dikshit R, et al. Cancer incidence and mortality worldwide: sources, methods and major patterns in GLOBOCAN 2012. Int J Cancer. 2015;136(5):E359-386.

3. Krishna Rao SV, Mejia G, Roberts-Thomson K, Logan R. Epidemiology of oral cancer in Asia in the past decade--an update (2000-2012). Asian Pac J Cancer Prev. 2013;14(10):5567-5577.

4. Curado MP, Edwards B, Shin HR, et al. Cancer incidence in five continents, vol. IX. Lyon, France: IARC Scientific Publications No. 160; 2007. Available from: http://ci5.iarc.fr/Default.aspx.

5. Liu SY, Lu CL, Chiou CT, et al. Surgical outcomes and prognostic factors of oral cancer associated with betel quid chewing and tobacco smoking in Taiwan. Oral Oncol. 2010;46(4):276-282.

6. Sankaranarayanan R, Swaminathan R, Brenner H, et al. Cancer survival in Africa, Asia, and Central America: a population-based study. Lancet Oncol. 2010;11(2):165-173.

7. Zhang J, Gao F, Yang AK, et al. Epidemiologic characteristics of oral cancer: single-center analysis of 4097 patients from the Sun Yat-sen University Cancer Center. Chin J Cancer. 2016;35:24.

8. Warnakulasuriya S. Global epidemiology of oral and oropharyngeal cancer. Oral Oncol. 2009;45(4-5):309-316.

9. Chaturvedi AK, Anderson WF, Lortet-Tieulent J, et al. Worldwide trends in incidence rates for oral cavity and oropharyngeal cancers. J Clin Oncol. 2013;31(36):4550-4559.

10. Corazziari I, Quinn M, Capocaccia R. Standard cancer patient population for age standardising survival ratios. Eur $J$ Cancer. 2004;40(15):2307-2316.

11. Listl S, Jansen L, Stenzinger A, et al. Survival of patients with oral cavity cancer in Germany. PLoS One. 2013;8(1):e53415.

12. Moore SR, Johnson NW, Pierce AM, Wilson DF. The epidemiology of tongue cancer: a review of global incidence. Oral Dis. 2000;6(2):75-84. 
13. Howlader N, Noone AM, Krapcho M, et al. editors. SEER Cancer Statistics Review, 1975-2012. Bethesda, MD: National Cancer Institute; 2015. Available from: https://seer.cancer.gov/statistics/.

14. Engholm G, Ferlay J, Christensen N, et al. NORDCAN--a Nordic tool for cancer information, planning, quality control and research. Acta Oncol. 2010;49(5):725-736.

15. Pires FR, Pringle GA, de Almeida OP, Chen SY. Intra-oral minor salivary gland tumors: a clinicopathological study of 546 cases. Oral Oncol. 2007;43(5):463-470.

16. Kakarala K, Bhattacharyya N. Survival in oral cavity minor salivary gland carcinoma. Otolaryngol Head Neck Surg. 2010;143(1):122-126.

17. Omura K. Current status of oral cancer treatment strategies: surgical treatments for oral squamous cell carcinoma. Int J Clin Oncol. 2014;19(3):423-430.

18. Iyer NG, Tan DS, Tan VK, et al. Randomized trial comparing surgery and adjuvant radiotherapy versus concurrent chemoradiotherapy in patients with advanced, nonmetastatic squamous cell carcinoma of the head and neck: 10-year update and subset analysis. Cancer. 2015;121(10):1599-1607.
19. Gore SM, Crombie AK, Batstone MD, Clark JR. Concurrent chemoradiotherapy compared with surgery and adjuvant radiotherapy for oral cavity squamous cell carcinoma. Head Neck. 2015;37(4):518-523.

20. Cohen EE, Karrison TG, Kocherginsky M, et al. Phase III randomized trial of induction chemotherapy in patients with N2 or N3 locally advanced head and neck cancer. J Clin Oncol. 2014;32(25):2735-2743.

21. Magrini SM, Buglione M, Corvò R, et al. Cetuximab and Radiotherapy Versus Cisplatin and Radiotherapy for Locally Advanced Head and Neck Cancer: A Randomized Phase II Trial. J Clin Oncol. 2016;34(5):427-435.

22. Husain ZA, Burtness BA, Decker RH. Cisplatin Versus Cetuximab With Radiotherapy in Locally Advanced Squamous Cell Carcinoma of the Head and Neck. J Clin Oncol. 2016;34(5):396-398.

23. Marta GN, William WN, Feher O, Carvalho AL, Kowalski LP. Induction chemotherapy for oral cavity cancer patients: Current status and future perspectives. Oral Oncol. 2015;51(12):1069-1075.

24. Fujii M. Recent multidisciplinary approach with molecular targeted drugs for advanced head and neck cancer. Int J Clin Oncol. 2014;19(2):220-229. 


\section{Supplementary material}

Table SI Demographic data for patients diagnosed with other pathologic types

\begin{tabular}{ll}
\hline Factor & All \\
\hline Patients, $\mathbf{n}$ & $\mathbf{1 6 6}$ \\
\hline Age at diagnosis, years & \\
\hline Mean age \pm SD & $49.2 \pm 16.7$ \\
Age range & $3-80$ \\
Gender, \% (n) & \\
Male & $63.3(105)$ \\
Female & $36.7(61)$ \\
Localization, \% (n) & \\
Lip & $10.2(17)$ \\
Tongue & $78.9(131)$ \\
Other parts & $10.8(18)$ \\
Type, \% (n) & \\
Sarcoma & $39.2(65)$ \\
Malignant melanoma & $23.5(39)$ \\
Sarcomatoid carcinoma & $12.7(21)$ \\
Basal cell carcinoma & $10.2(17)$ \\
Malignant neurilemmoma & $7.8(13)$ \\
Malignant fibrous histiocytoma & $6.6(11)$ \\
\hline
\end{tabular}

Table S2 Five-year OS of patients diagnosed with cancer of the lip, cancer of the tongue, and cancer within other parts of oral cavity, 1960-2009

\begin{tabular}{|c|c|c|c|c|c|c|c|}
\hline \multirow[t]{2}{*}{ Factor } & \multirow[t]{2}{*}{ Level } & \multicolumn{2}{|l|}{ Lip } & \multicolumn{2}{|c|}{ Tongue } & \multicolumn{2}{|c|}{ Other parts } \\
\hline & & $\mathbf{N}$ & $\begin{array}{l}\text { 5-year OS } \\
\text { (\%) }\end{array}$ & $\mathbf{N}$ & $\begin{array}{l}\text { 5-year OS } \\
\text { (\%) }\end{array}$ & $\mathbf{N}$ & $\begin{array}{l}\text { 5-year OS } \\
\text { (\%) }\end{array}$ \\
\hline All & & 148 & 71.4 & 1,823 & 56.3 & $\mathrm{I}, 176$ & 42.7 \\
\hline \multirow[t]{5}{*}{ Age, years } & $\leq 44$ & 23 & 81.9 & 578 & 61.6 & 229 & 52.4 \\
\hline & $45-54$ & 28 & 71.4 & 490 & 58.9 & 277 & 45.2 \\
\hline & $55-64$ & 49 & 77.2 & 475 & 54.2 & 415 & 40.1 \\
\hline & $65-74$ & 34 & 72.2 & 230 & 47.2 & 216 & 36.8 \\
\hline & $\geq 75$ & 14 & 31.2 & 50 & 31.5 & 39 & 29.6 \\
\hline \multirow[t]{2}{*}{ Gender } & Male & 108 & 72.0 & 1,150 & 54.9 & 836 & 40.4 \\
\hline & Female & 40 & 69.6 & 673 & 58.8 & 340 & 48.4 \\
\hline \multirow[t]{3}{*}{ Type } & SCC & 126 & 69.5 & 1,798 & 56.1 & 921 & 39.2 \\
\hline & MSGC & 5 & 80.0 & 13 & 69.2 & 149 & 69.8 \\
\hline & Others & 17 & 82.4 & 12 & 66.7 & 106 & 36.8 \\
\hline \multirow[t]{4}{*}{ Stage } & Local & 85 & 68.5 & 1,114 & 67.7 & 490 & 52.4 \\
\hline & Regional & 8 & 50.0 & 455 & 36.0 & 322 & 26.2 \\
\hline & Distant & 0 & - & 9 & II.I & 18 & 14.8 \\
\hline & Unknown & 55 & 79.3 & 245 & 42.4 & 346 & 45.4 \\
\hline \multirow[t]{2}{*}{ Therapy } & Surgery & 143 & 71.8 & 1,363 & 66.2 & 891 & 50.1 \\
\hline & Non-surgery & 5 & 60.0 & 460 & 26.3 & 285 & 18.8 \\
\hline
\end{tabular}

Abbreviations: OS, overall survival; SCC, squamous cell carcinoma; MSGC, minor salivary gland carcinoma. 
Table S3 Five-year OS of patients diagnosed with cancer of oral cavity parts other than lip and tongue (gingiva, floor of mouth, hard palate, and buccal mucosa), 1960-2009

\begin{tabular}{|c|c|c|c|c|c|c|c|c|c|}
\hline \multirow[t]{2}{*}{ Factor } & \multirow[t]{2}{*}{ Level } & \multicolumn{2}{|c|}{ Gingiva } & \multicolumn{2}{|c|}{ Floor of mouth } & \multicolumn{2}{|c|}{ Hard palate } & \multicolumn{2}{|c|}{ Buccal mucosa } \\
\hline & & $N$ & $\begin{array}{l}\text { 5-year OS } \\
\text { (\%) }\end{array}$ & $\mathbf{N}$ & $\begin{array}{l}\text { 5-year OS } \\
\text { (\%) }\end{array}$ & $N$ & $\begin{array}{l}\text { 5-year OS } \\
\text { (\%) }\end{array}$ & $\mathbf{N}$ & $\begin{array}{l}\text { 5-year OS } \\
\text { (\%) }\end{array}$ \\
\hline All & & 435 & 38.7 & 229 & 42.2 & 250 & 48.1 & 262 & 44.8 \\
\hline \multirow[t]{5}{*}{ Age, years } & $\leq 44$ & 79 & 45.4 & 29 & 49.7 & 74 & 62.0 & 47 & 51.2 \\
\hline & $45-54$ & 94 & 42.8 & 66 & 48.3 & 56 & 50.1 & 60 & 42.3 \\
\hline & $55-64$ & 162 & 36.8 & 93 & 36.8 & 74 & 44.5 & 86 & 45.9 \\
\hline & $65-74$ & 84 & 36.9 & 35 & 41.7 & 38 & 29.3 & 59 & 38.0 \\
\hline & $\geq 75$ & 16 & 13.5 & 6 & 33.3 & 8 & 26.0 & 9 & 62.5 \\
\hline \multirow[t]{2}{*}{ Gender } & Male & 298 & 39.3 & 204 & 40.4 & 158 & 40.8 & 175 & 41.9 \\
\hline & Female & 137 & 37.4 & 25 & 56.0 & 92 & 60.2 & 86 & 50.7 \\
\hline \multirow[t]{3}{*}{ Type } & SCC & 347 & 40.4 & 209 & 41.8 & 135 & 30.3 & 229 & 40.2 \\
\hline & MSGC & 24 & 56.2 & 16 & 43.3 & 91 & 73.1 & 18 & 94.4 \\
\hline & Others & 64 & 23.9 & 4 & 66.7 & 24 & 56.4 & 14 & 53.7 \\
\hline \multirow[t]{4}{*}{ Stage } & Local & 184 & 48.6 & 106 & 50.8 & 100 & 53.3 & 100 & 60.4 \\
\hline & Regional & 114 & 21.5 & 77 & 32.8 & 37 & 22.2 & 93 & 28.4 \\
\hline & Distant & 8 & 15.6 & 3 & 0 & 6 & 22.2 & 0 & - \\
\hline & Unknown & 129 & 41.5 & 43 & 39.6 & 107 & 53.5 & 67 & 44.7 \\
\hline \multirow[t]{2}{*}{ Therapy } & Surgery & 336 & 46.3 & 164 & 51.4 & 194 & 56.0 & 197 & 50.0 \\
\hline & Non-surgery & 99 & 13.1 & 65 & 15.6 & 56 & 21.0 & 64 & 28.4 \\
\hline
\end{tabular}

Abbreviations: OS, overall survival; SCC, squamous cell carcinoma; MSGC, minor salivary gland carcinoma.

Table S4 Five-year OS of patients diagnosed with oral cavity cancer by sex and tumor localization, 2000-2009

\begin{tabular}{|c|c|c|c|c|c|c|c|}
\hline \multirow[t]{2}{*}{ Factor } & \multirow[t]{2}{*}{ Level } & \multirow{2}{*}{$\begin{array}{l}\text { Overall } \\
\text { (\%) }\end{array}$} & \multicolumn{2}{|c|}{ Gender } & \multicolumn{3}{|c|}{ Localization } \\
\hline & & & $\begin{array}{l}\text { Male } \\
(\%)\end{array}$ & $\begin{array}{l}\text { Female } \\
(\%)\end{array}$ & $\begin{array}{l}\text { Lip } \\
\text { (\%) }\end{array}$ & $\begin{array}{l}\text { Tongue } \\
\text { (\%) }\end{array}$ & $\begin{array}{l}\text { Other parts } \\
(\%)\end{array}$ \\
\hline All & & 55.6 & 50.5 & 65.0 & 84.1 & 62.2 & 43.9 \\
\hline \multirow[t]{5}{*}{ Age, years } & $\leq 44$ & 66.5 & 62.1 & 74.0 & 75.0 & 70.2 & 55.9 \\
\hline & $45-54$ & 58.6 & 50.4 & 75.1 & 100.0 & 65.0 & 45.9 \\
\hline & $55-64$ & 51.6 & 47.3 & 59.1 & 100.0 & 59.0 & 42.6 \\
\hline & $65-74$ & 50.8 & 46.2 & 59.2 & 100.0 & 57.7 & 37.1 \\
\hline & $\geq 75$ & 32.2 & 30.2 & 35.0 & 50.0 & 20.0 & 39.2 \\
\hline \multirow[t]{2}{*}{ Gender } & Male & 50.5 & 1 & 1 & 86.7 & 57.3 & 39.6 \\
\hline & Female & 65.0 & 1 & 1 & 80.0 & 69.9 & 54.4 \\
\hline \multirow[t]{3}{*}{ Type } & SCC & 54.4 & 49.5 & 63.8 & 83.3 & 62.1 & 38.9 \\
\hline & MSGC & 74.0 & 66.9 & 79.4 & 100.0 & 75.0 & 73.5 \\
\hline & Others & 60.5 & 59.9 & 62.0 & 80.0 & - & 56.9 \\
\hline \multirow[t]{7}{*}{ Localization } & Lip & 84.1 & 86.7 & 80.0 & I & I & 1 \\
\hline & Tongue & 62.2 & 57.3 & 69.9 & I & I & I \\
\hline & Other parts & 43.9 & 39.6 & 54.4 & 1 & 1 & I \\
\hline & Floor of mouth & 35.8 & 33.7 & 60.0 & I & I & I \\
\hline & Gingiva & 45.6 & 46.7 & 43.2 & I & I & I \\
\hline & Hard palate & 47.8 & 34.2 & 66.2 & I & l & I \\
\hline & Buccal mucosa & 47.2 & 40.0 & 57.5 & 1 & I & I \\
\hline \multirow[t]{4}{*}{ Stage } & Local & 69.3 & 64.7 & 77.2 & 78.6 & 75.6 & 55.0 \\
\hline & Regional & 31.2 & 26.6 & 39.9 & 100.0 & 33.4 & 27.8 \\
\hline & Distant & 12.5 & 0 & 25.0 & - & 33.3 & 0 \\
\hline & Unknown & 55.9 & 50.5 & 69.6 & 90.5 & 49.8 & 53.9 \\
\hline \multirow[t]{2}{*}{ Therapy } & Surgery & 65.1 & 61.1 & 71.5 & 84.1 & 71.5 & 53.4 \\
\hline & Non-surgery & 17.6 & 15.1 & 25.2 & - & 20.8 & 13.2 \\
\hline
\end{tabular}

Notes: "l" means NA since the variant in the line and the variant in the column were the same. "-" means none of the cases could be sorted to this group.

Abbreviations: OS, overall survival; SCC, squamous cell carcinoma; MSGC, minor salivary gland carcinoma. 


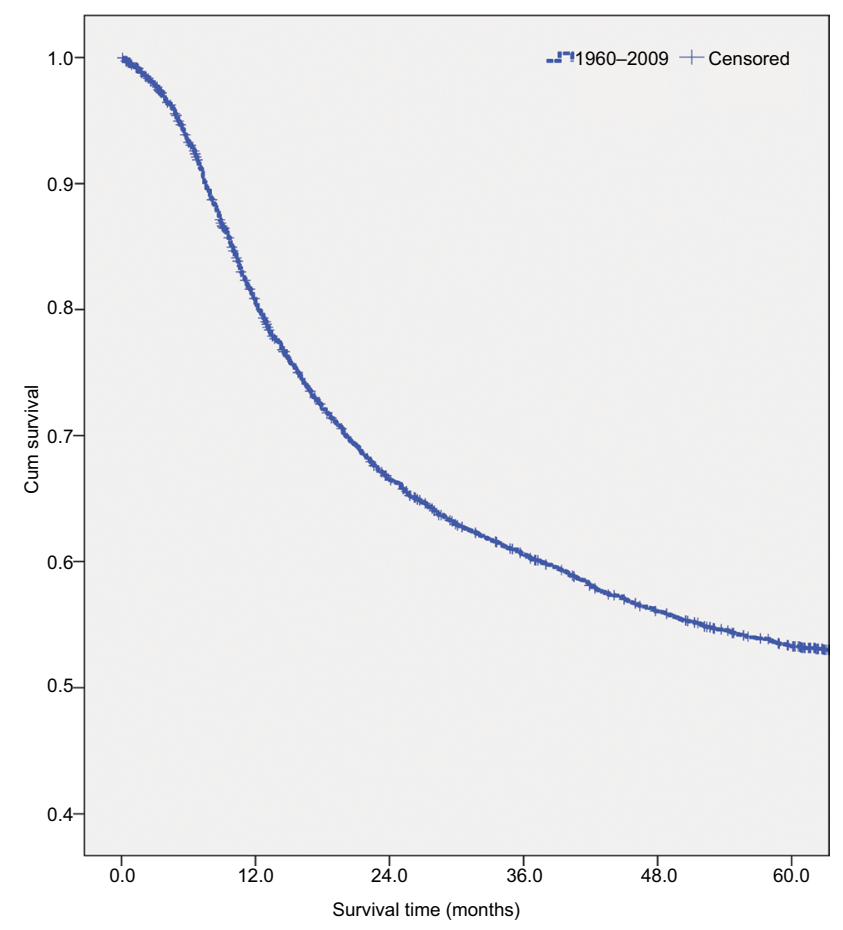

Figure SI Survival curve for all patients diagnosed with oral cavity cancer from 1960 to 2009.

Abbreviation: cum, cumulative.

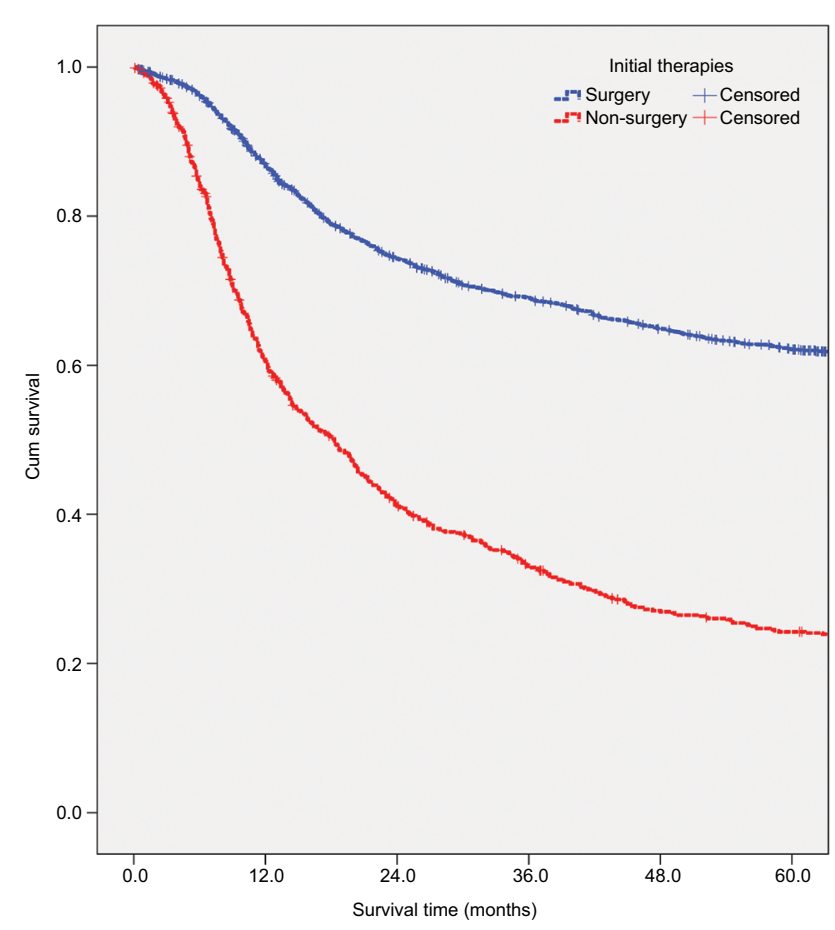

Figure S2 Survival curves for all-cause mortality for patients diagnosed with oral cavity cancer by initial therapy (surgery and non-surgery) $(P<0.00 \mathrm{I})$.

Abbreviation: cum, cumulative.

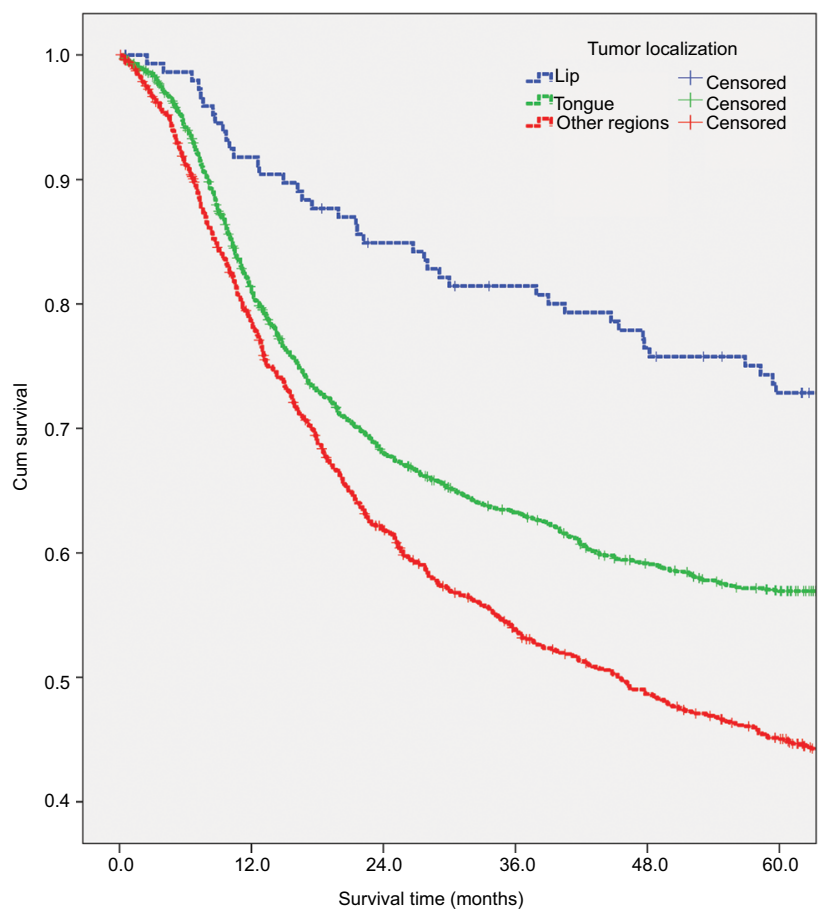

Figure S3 Survival curves for all-cause mortality for patients diagnosed with oral cavity cancer by tumor localization (lip, tongue, and other parts of oral cavity) $(P<0.00$ I for all).

Abbreviation: cum, cumulative.

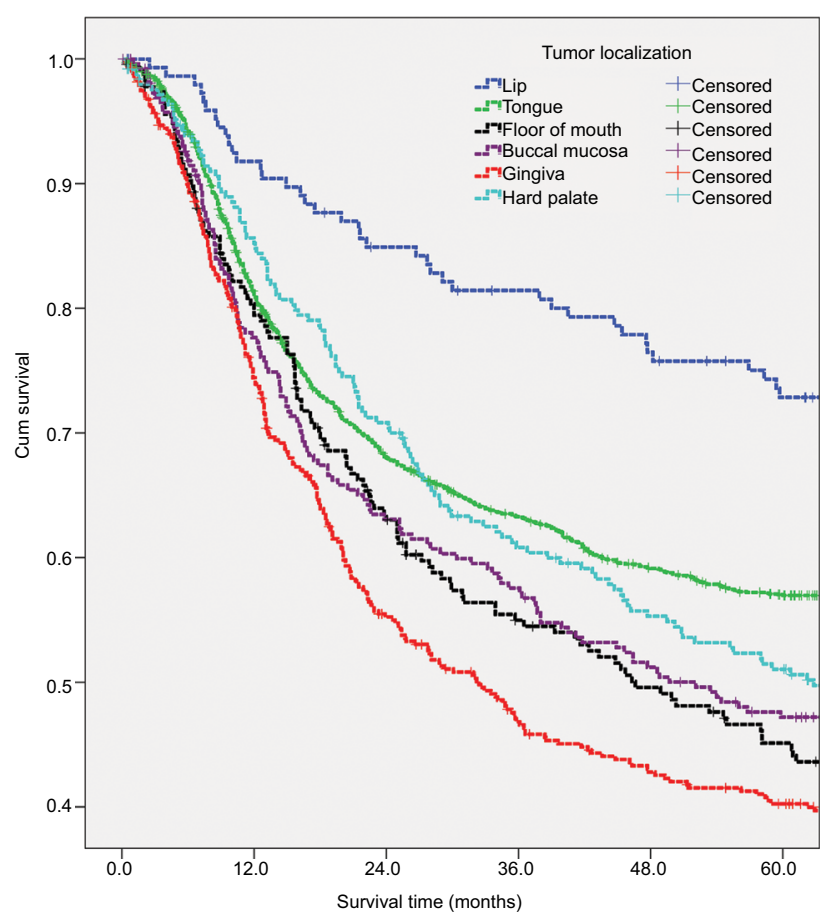

Figure S4 Survival curves for all-cause mortality for patients diagnosed with oral cavity cancer by tumor localization (lip, tongue, floor of mouth, gingiva, hard palate, and buccal mucosa) $(P<0.00$ I for all).

Abbreviation: cum, cumulative. 
Cancer Management and Research

\section{Publish your work in this journal}

Cancer Management and Research is an international, peer-reviewed open access journal focusing on cancer research and the optimal use of preventative and integrated treatment interventions to achieve improved outcomes, enhanced survival and quality of life for the cancer patient.

The manuscript management system is completely online and includes

Submit your manuscript here: https://www.dovepress.com/cancer-management-and-research-journal

a very quick and fair peer-review system, which is all easy to use. Visit $\mathrm{http}: / / \mathrm{www}$.dovepress.com/testimonials.php to read real quotes from published authors. 